Cómo citar este trabajo: Martínez Cano, M. (2020). Violencias hacia las personas que ejercen la prostitución en la Región de Murcia: Revista del Laboratorio Iberoamericano para el Estudio Sociohistórico de las Sexualidades, 04 art. 12, 227-251. https://doi.org/10.46661/ relies.5062

\title{
Violencias hacia las personas que ejercen la prostitución en la Región de Murcia
}

\section{Violences towards people who engage in prostitution in the Region of Murcia}

\author{
María Martínez Cano ${ }^{1}$ \\ Graduada en Psicología (Universidad de Murcia) \\ Máster Universitario en Políticas Sociales e Intervención Sociocomunitaria. \\ Especialización en género y políticas de igualdad (Universidade da Coruña, Facultade de \\ Socioloxia) \\ maria.martinezcano.psi@gmail.com
}

\section{Resumen}

Este estudio se centra en visibilizar las violencias perpetradas hacia las personas que ejercen la prostitución en la Región de Murcia (España), poniendo en relieve a los diferentes colectivos que las protagonizan. La hipótesis de partida es que la salud, las condiciones laborales y las relaciones interpersonales de los y las trabajadoras del sexo están determinadas por la articulación de una cadena de violencias ejercidas por diferentes agentes sociales. La metodología está basada en una serie de entrevistas semidirigidas en las que se han tenido en cuenta dos perspectivas: la de nueve personas que ejercen la prostitución y la de siete expertos/as en investigación e intervención directa con trabajadoras/es del sexo. En el análisis de resultados el contenido se organizó atendiendo a los diferentes grupos que se identificaron como responsables de los actos violentos: profesionales sanitarios/as, trabajadores/as de los servicios sociales, políticos/as, cuerpos de seguridad estatal,

\footnotetext{
${ }^{1}$ NOTA DE LA AUTORA Este artículo es una adaptación del Trabajo Fin de Máster que realicé en el Máster Universitario en Políticas Sociales e Intervención Sociocomunitaria, durante el curso 2018-2019, en la Universidad de La Coruña. Quisiera mostrar mi agradecimiento a todas las personas que han hecho posible este estudio: a los y las trabajadoras del sexo que tan generosamente compartieron conmigo algunos fragmentos de sus vidas; al equipo de profesionales del Comité de Apoyo a las Trabajadoras del Sexo por el entusiasmo mostrado durante su colaboración en este proyecto; y a mi directora de TFM, Laura Oso Casas, por su apoyo, atención y enseñanzas.
} 
entidades del tercer sector, secciones feministas, empresariado de la industria del sexo, clientela, investigadores/as vinculados a la academia, medios de comunicación, familiares, parejas, exparejas, amistades y otros/as responsables.

Palabras clave: estigma, prostitución, trabajo sexual, violencia.

\section{Abstract}

The aim of this study is to raise awareness about the acts of violence perpetrated towards people who engage in prostitution in the Region of Murcia, emphasising the importance of the collectives who are responsible. The starting point hypothesis is that health, working conditions and social relationships of sex workers are determined by the organization of violences series practiced by different social agents. The methodology is based on a series of semi-directed interviews in which two dissimilar perspectives have been takin into account: nine sex workers and seven experts in investigation and straightforward intervention with sex workers. Furthermore, for the analysis of the results, the content was organized attending to the different groups who were identified as responsible of the violent acts: sanitary professionals, social services professionals, politicians, law enforcement agents, feminist segments, sex industry businessmen, clients, researchers, media, relatives, partners, ex-partners, friends and others in charge.

Key words: stigma, prostitution, sex work, violence. 


\section{Introducción}

Cuando se habla de prostitución y de violencias se tiende a pensar en las agresiones ejercidas por los clientes y por el empresariado de la industria del sexo. Incluso, habitualmente se piensa en las mafias relacionadas con la trata, ya que no es infrecuente que se equipare la prostitución con la trata de personas con fines de prostitución forzada ${ }^{2}$. Es incuestionable la importancia de denunciar los abusos cometidos por la clientela y por los/las responsables de los pisos de contactos y de los clubes, pero el trabajo sexual está sometido a otro tipo de violencias que son menos visibles. El interés de esta investigación reside en que permite describir este tipo de violencias y sus efectos, a la vez que sitúa el foco en la identificación de los diferentes colectivos por los que están protagonizadas. La hipótesis de partida es que la salud (física y psicológica), las condiciones laborales y las relaciones sociales de las personas que deciden ejercer la prostitución (en adelante PDEP) están determinadas por la articulación de una cadena de violencias practicadas por diferentes actores y actrices sociales.

En cuanto a la situación de la prostitución en la Región de Murcia (España), a pesar su disminución en la vía pública, (debido a la proliferación de clubes de alterne y de pisos de contactos) siguen existiendo zonas de prostitución de calle bastante populares, tanto a las afueras de los pueblos como en la ciudad de Murcia. Un ejemplo relevante es el céntrico Barrio del Carmen, en el que se está aplicando la «Ordenanza para luchar contra la prostitución en el municipio de Murcia», la cual tiene por objeto:

"Luchar contra la prostitución, preservando los espacios públicos como lugares de convivencia, civismo e igualdad, evitando actividades de explotación sexual que difunden una imagen del ser humano, muy especialmente de la mujer, como mero objeto sexual y que perturban la convivencia social." (BORM no 234, 2013:2).

A pesar de que en dicha ordenanza se afirma que uno de los principales propósitos es el fomento y la promoción de la igualdad entre hombres y mujeres, lo cierto es que mayoritariamente se multa a mujeres migrantes con pocos recursos que captan a su clientela en la vía pública, empeorando así su situación de vulnerabilidad. A partir de dos estudios realizados por el Comité de Apoyo a las Trabajadoras del Sexo (CATS, 2014, 2018) ${ }^{3}$ se ha evidenciado que la aplicación de medidas punitivas anti-prostitución, como la ordenanza o la Ley Orgánica 4/2015 de protección de la seguridad

\footnotetext{
${ }^{2}$ Conviene subrayar que en este estudio me centraré en analizar las violencias relacionadas con la explotación laboral y no las relativas a la trata de personas con fines de prostitución forzada, ya que constituye un fenómeno diferente a la prostitución. En la prostitución (entendida como una modalidad de trabajo sexual) se produce un intercambio comercial consensuado entre adultos, mientras que en la trata de personas con fines de prostitución forzada se está cometiendo un delito

${ }^{3}$ El Comité de Apoyo a las Trabajadoras del Sexo (CATS) es una asociación con sede en la ciudad de Murcia, que lleva dieciocho años proporcionando servicios y defendiendo los derechos de los y las trabajadoras del sexo, desde el respeto a su decisión individual de permanecer o cambiar de actividad laboral. El CATS atiende en diferentes ámbitos y momentos, ofreciendo a cada persona una atención individualizada, la cual se consigue a través de tres niveles de actuación: visita a los lugares de trabajo, atención en el local y teléfono de emergencia. Asimismo, los servicios que ofrece la asociación están divididos en diferentes áreas de intervención:
}

Área de acogida y recepción. Área de salud. Área legal. Área social. Área laboral y formativa. Área de investigación sociológica. Área de sensibilización social.

Revista del Laboratorio Iberoamericano para el Estudio

Sociohistórico de las Sexualidades 
ciudadana (conocida como ley mordaza), han contribuido al agravamiento de la discriminación y la precarización que ya sufrían las PDEP, tal y como podemos observar en la figura 1

Figura 1. Principales consecuencias de la Ordenanza para luchar contra la prostitución en el municipio de Murcia.

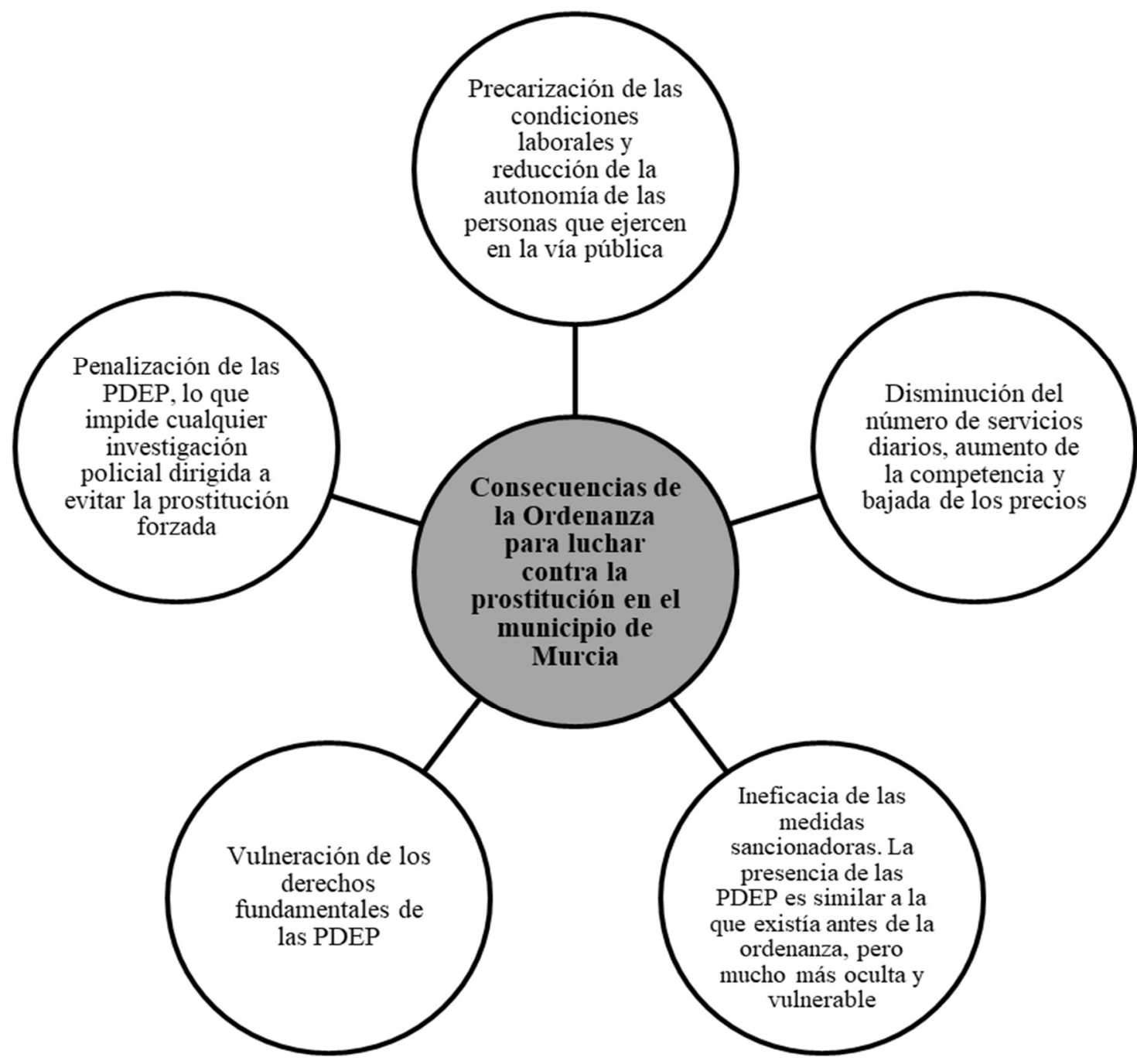

Fuente: Elaboración propia, a partir de CATS $(2014,2018)$

Hay que mencionar, además, la dificultad de proporcionar información precisa sobre el conjunto de las personas que se dedican a una actividad tan estigmatizada y criminalizada como la prostitución, la cual se caracteriza por una gran movilidad de las PDEP y por pertenecer a la economía sumergida (CATS, 2017a). No obstante, a pesar de que no se disponen de datos fiables sobre las personas que ejercen en la Región de Murcia, se pueden tomar a modo de orientación los datos recabados por entidades como el CATS. Entre las personas trabajadoras del sexo atendidas por esta ONG en el año 2017 (1.857 usuarias/os en total), la mayoría procedían de Rumanía (468), seguidas por mujeres de nacionalidad colombiana (241) y marroquí (216). Por otro lado, en los resultados de una investigación-acción participativa desarrollada por la socióloga Sara Oñate (2009) en la Región de Murcia, se mostró un alto grado de autogestión por parte de las personas trabajadoras del sexo. Igualmente, en el presente estudio las PDEP que participaron afirmaron no sentirse obligadas/os por nadie a trabajar, aunque consideraban que era una decisión que estaba condicionada por estructuras socioeconómicas. 


\section{Consideraciones Metodológicas}

La investigación presentada es cualitativa y exploratoria en vista de que, mediante la revisión teórica y las entrevistas semidirigidas, se realizó un acercamiento a las violencias ejercidas hacia las personas que trabajan (o han trabajado) en la prostitución en la Región de Murcia. En primer lugar, con el objetivo de profundizar en las experiencias de violencia de las PDEP, fue necesario realizar una contextualización de este colectivo. Para ello, se llevó a cabo una explotación de datos secundarios sobre cuestiones relativas a la prostitución: espacios y ámbitos de trabajo, legislaciones nacionales e internacionales, investigaciones sobre trabajo sexual desarrolladas en Murcia, autobiografías de trabajadoras sexuales, testimonios sobre violencias, etc. En segundo lugar, se realizaron entrevistas semidirigidas a nueve personas que ejercen (o ejercieron) la prostitución y a siete expertas/os en contextos de investigación y/o intervención directa. Un total de dieciséis personas fueron entrevistadas.

Los criterios de selección para las PDEP fueron dos: ser mayor de edad y ejercer o haber ejercido la prostitución en la Región de Murcia. En el caso de las/os profesionales en materia de trabajo sexual se optó por personas que llevasen al menos dos años en contacto directo con la realidad estudiada, puesto que la experiencia es una variable aliada a la hora de obtener información relevante. Un requisito común para todas/os las/os participantes fue que, tras explicarles los objetivos del estudio, en qué consistía su participación, el compromiso de confidencialidad y los riesgos y beneficios, expresaran oralmente el consentimiento informado para participar. Con la finalidad de mantener el anonimato de las personas entrevistadas solo se hará referencia a la información recogida en la tabla 1 y en las siguientes descripciones:

Trabajadora sexual española (TS.1): vive en Barcelona, pero se desplaza a diferentes zonas de España para trabajar, entre ellas la Región de Murcia. Trabaja de forma independiente, alquilando habitaciones acondicionadas para el ejercicio de la prostitución. Actualmente, además de dedicarse al trabajo sexual, está finalizando el Grado en Psicología. En total ha trabajado durante cinco años en prostitución, sin embargo, afirma que lleva diez años cargando con el peso del estigma: desde que decidió empezar a ejercer cuando tenía veintitrés años.

- Trabajadora sexual española (TS.2): empezó a ejercer con dieciocho años de forma independiente. Siente que los clientes no respetan su trabajo ni su condición de mujer transexual. Aun así, considera que la prostitución es una buena opción laboral para ella por la libertad que le proporciona a la hora de escoger horarios y por los ingresos que obtiene. Sobre todo, considera positivo que el trabajo sexual le permita conciliar con su faceta de madre de un niño de tres años.

- Trabajadora sexual mexicana (TS.3): se dedica al trabajo sexual en diferentes ámbitos: asistencia sexual, prostitución y pornografía. Además, ha desarrollado numerosos proyectos artísticos relacionados con la reivindicación de los derechos de las personas migrantes y de los y las trabajadoras del sexo. Está casada, tiene una hija adolescente y reside en España con una situación administrativa regular.

- $\quad$ Trabajador sexual ecuatoriano (TS.4): empezó a trabajar en prostitución cuando llegó a España hace veinte años. Siempre ha ejercido de forma independiente, y para desarrollar su trabajo suele vestir con ropa "típicamente femenina". La mayoría de sus clientes son hombres casados con mujeres que no se atreven a mostrar su atracción sexual hacia otros hombres. Este trabajador sexual se dedicaba a la enseñanza en su país natal, Ecuador, pero debido a la homofobia de sus familiares decidió migrar a España. En la actualidad, reside en el municipio de Murcia con una situación administrativa regular. 
- Trabajadora sexual ecuatoriana (TS.5): capta a sus clientes en una zona comercial situada a las afueras del municipio de Murcia. Lleva veintidós años ejerciendo, y considera que su mayor problema en relación con la prostitución es la escasez de clientes y la consiguiente disminución de sus ingresos. Su principal demanda es que las instituciones escuchen a los y las trabajadoras del sexo antes de elaborar legislaciones que tengan que ver con ellas/os. Su situación administrativa en España está regularizada, y reside en un piso cercano a su espacio de trabajo.

- $\quad$ Trabajadora sexual peruana (TS.6): ha trabajado de forma esporádica en prostitución, tanto en su país de origen como en España. Desde hace un año y medio ejerce regularmente en la Región de Murcia, de forma independiente y en habitaciones de alquiler enfocadas a la prostitución de lujo. Para ella el trabajo sexual es una gracia, puesto que le reporta altos beneficios económicos y le permite dar rienda suelta a sus apetencias sexuales. No obstante, admite que, a veces, se siente superada por tener que llevar una doble vida, ya que sus hijas y su familia no saben a qué se dedica. Su situación administrativa en España está regularizada, y reside en un pueblo cercano a la ciudad de Murcia.

Trabadora sexual española (TS.7): trabaja de forma independiente captando a su clientela en la calle, concretamente en un polígono industrial situado a las afueras del municipio de Murcia. Lleva once meses ejerciendo en la Región de Murcia, pero también ha trabajado en clubs de alterne en Marbella. Esta trabajadora afirma que ejerce en momentos muy puntuales para superar baches económicos. Hace cinco años ejerció por primera vez. Anteriormente, regentaba una boutique de modas.

- $\quad$ Trabajadora sexual brasileña (TS.8): lleva trabajando en prostitución diecisiete años. Llegó a España engañada, pensando que iba a trabajar como camarera. Estuvo un año ejerciendo la prostitución forzadamente para pagar la deuda de viaje. Posteriormente, decidió seguir ejerciendo prostitución porque es el trabajo que le resultaba más rentable económicamente. Tiene formación de azafata de vuelo, de profesora de zumba, de masajista y habla tres idiomas. Afirma encontrarse cómoda ejerciendo la prostitución de forma independiente en su piso y (eventualmente) en clubes, no obstante, sigue formándose por si en un futuro quisiera abandonar el trabajo sexual. Su situación administrativa en España está regularizada y vive en la ciudad de Murcia.

- $\quad$ Trabajadora sexual española (TS.9): empezó a ejercer de forma independiente hace un año y medio. En la actualidad no se dedica a la prostitución. Trabaja como camarera en un restaurante, y está enfocada en terminar de formarse como trabajadora social. En un futuro no descarta volver a ejercer, ya que está satisfecha con los beneficios económicos del trabajo sexual. Participa en varias entidades de apoyo a los derechos de los y las trabajadoras del sexo, puesto que considera que su faceta como activista es la mejor forma de afrontar el estigma por haber ejercido la prostitución.

- Coordinador de proyectos (PR.1): su función consiste en encargarse de coordinar las acciones que se desarrollan en el CATS: desde participaciones en debates y ruedas de prensa, al desarrollo de manifestaciones o reuniones de equipo. También realiza labores administrativas.

Médica de familia especializada en sexualidad y salud reproductiva/ITS (PR.2): se encarga del área de salud del CATS, que es la más demandada. Es especialista en ITS (Infecciones de Transmisión Sexual). También atiende otro tipo de consultas e imparte cursos de educación para la salud.

Educadora social (PR.3): sus competencias se encuadran dentro de la educación no formal de personas adultas, concretándose en la educación para la salud. Sus funciones y tareas específicas son: visitas a los lugares de trabajo (clubes de alterne), gestión del voluntariado, sensibilización social y tutorización del alumnado en prácticas. 
- $\quad$ Educadora social (PR.4): esta educadora social realiza las mismas funciones que su análoga. Actualmente, también está centrada en la gestión de las redes sociales de la entidad, con el objetivo de difundir las acciones realizadas por el CATS e información relacionada con el trabajo sexual a nivel nacional e internacional.

- $\quad$ Trabajadora social (PR.5): forma parte del área laboral, y se encarga de buscar trabajos alternativos o complementarios para las trabajadoras y trabajadores sexuales que lo soliciten, procurando mejorar las condiciones laborales de quienes deciden seguir ejerciendo la prostitución.

- Abogada (PR.6): ofrece asesoramiento legal sobre cualquier tema (divorcios, multas, custodia de hijos e hijas, impagos, desahucios, arraigo social, reagrupación familiar, etc.), y también ayuda en la presentación de denuncias realizando un seguimiento jurídico.

- $\quad$ Trabajadora social (PR.7): se encarga del área social, y su labor está centrada en mejorar las condiciones de vida de las personas que ejercen la prostitución y de sus familiares, lo que implica ofrecer información y apoyo en trámites de extranjería y administrativos, atender situaciones relacionadas con hijas/os, gestionar ayudas económicas, asesorar en la búsqueda de vivienda, etc.

Tabla 1. Perfil socioeconómico de los/as informantes

\begin{tabular}{|c|c|c|c|c|c|}
\hline Entrevistada/o & Sexo/Género & Edad & Residencia & Nacionalidad & Empleo \\
\hline TS.1 & Mujer & 33 & Barcelona & Española & $\begin{array}{l}\text { Trabajadora sexual independiente. } \\
\text { Habitaciones alquiladas. }\end{array}$ \\
\hline TS.2 & Mujer trans & 22 & Murcia & Española & $\begin{array}{l}\text { Trabajadora sexual independiente. } \\
\text { Salidas a hoteles. }\end{array}$ \\
\hline TS.3 & Mujer & 43 & Murcia & Mexicana & $\begin{array}{l}\text { Trabajadora sexual ejerciendo en } \\
\text { clubes y de forma independiente. }\end{array}$ \\
\hline TS.4 & Hombre & 47 & Murcia & Ecuatoriana & $\begin{array}{l}\text { Trabajador sexual independiente. } \\
\text { Captación en calle. }\end{array}$ \\
\hline TS.5 & Mujer trans & 45 & Murcia & Ecuatoriana & $\begin{array}{l}\text { Trabajadora sexual independiente. } \\
\text { Captación en calle. }\end{array}$ \\
\hline TS.6 & Mujer & 35 & Murcia & Peruana & $\begin{array}{l}\text { Trabajadora sexual independiente. } \\
\text { Habitaciones alquiladas. }\end{array}$ \\
\hline TS.7 & Mujer & 50 & Murcia & Española & $\begin{array}{l}\text { Trabajadora sexual independiente. } \\
\text { Captación en calle. }\end{array}$ \\
\hline TS.8 & Mujer & 33 & Murcia & Brasileña & $\begin{array}{l}\text { Trabajadora sexual ejerciendo en } \\
\text { clubes y de forma independiente. }\end{array}$ \\
\hline TS.9 & Mujer & 27 & Murcia & Española & $\begin{array}{l}\text { Trabajadora sexual independiente. } \\
\text { Salidas a hoteles. }\end{array}$ \\
\hline PR.1 & Hombre & 56 & Murcia & Española & Coordinador de proyectos \\
\hline PR.2 & Mujer & 60 & Murcia & Española & Ginecóloga \\
\hline PR.3 & Mujer & 35 & Murcia & Española & Educadora Social \\
\hline PR.4 & Mujer & 29 & Murcia & Española & Educadora Social \\
\hline PR.5 & Mujer & 40 & Murcia & Española & Trabajadora social y socióloga \\
\hline PR.6 & Mujer & 42 & Murcia & Española & Abogada \\
\hline PR.7 & Mujer & 40 & Murcia & Española & Trabajadora Social \\
\hline
\end{tabular}

Fuente: elaboración propia 
Las entrevistas se realizaron de una forma semiestructurada porque se quería indagar sobre categorías muy concretas, pero a su vez se requería cierta flexibilidad para que los y las entrevistadas pudieran expresar posibles aspectos no contemplados en el guion (figura 2) (Valles, 2002). Esta técnica tiene la ventaja de que es la propia voz de la persona entrevistada la que revela su experiencia, lo que refleja la cantidad de matices y variables que están detrás de las diferentes experiencias de violencias. Por otro lado, el hecho de que las conversaciones estuvieran dirigidas a profundizar en cuestiones íntimas y dolorosas hizo necesario que se creara un clima de confianza y empatía con las PDEP participantes, para lo cual la técnica de la entrevista es adecuada.

Figura 2. Guion de la entrevista semidirigida: bloques temáticos

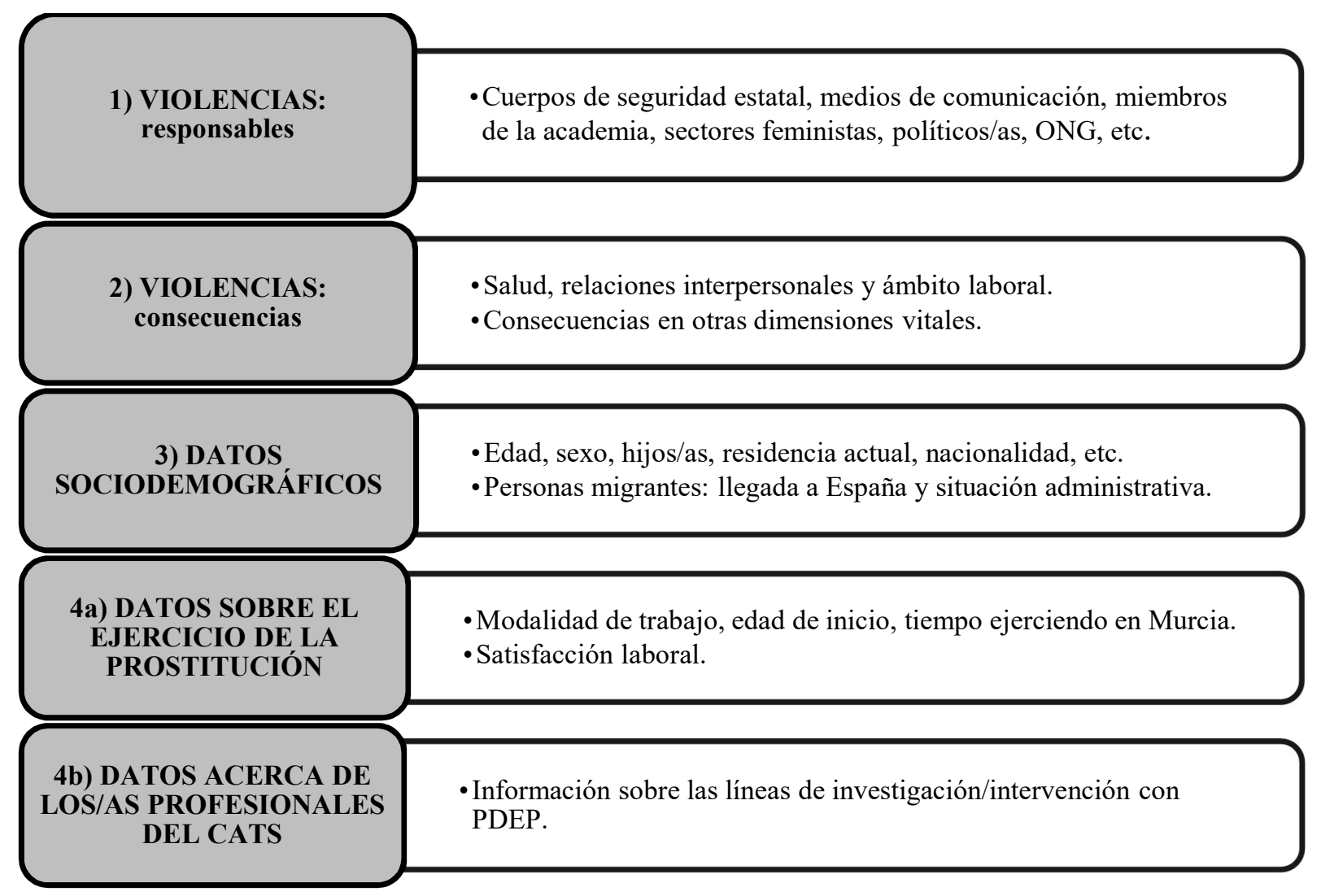

Fuente: Elaboración propia

Durante el desarrollo del trabajo de campo se contó con la colaboración del Comité de Apoyo a las Trabajadoras del Sexo, de manera que fue posible la realización de entrevistas a sus empleadas/os y a algunas de las personas usuarias que participan de forma activa en la entidad. Por otro lado, se realizaron salidas a lugares de ejercicio de la prostitución en compañía de miembros del CATS, a través de las/os que se estableció contacto con personas que ejercen la prostitución, utilizándose así el muestreo en cadena o bola de nieve. Las entrevistas se realizaron en diversos lugares: ocho de ellas en la sede del CATS, cinco en cafeterías, dos en los domicilios particulares de las trabajadoras del sexo y una en la zona de captación de la clientela de una de las entrevistadas (tabla 2). 
Tabla 2. Lugar de realización y número de entrevistas

\begin{tabular}{|l|l|}
\hline Lugar de realización de las entrevistas & N. ${ }^{\circ}$ de entrevistas \\
\hline Sede CATS & 8 \\
\hline Cafetería & 5 \\
\hline Domicilio particular & 2 \\
\hline Lugar de trabajo: zona de prostitución en calle & 1 \\
\hline
\end{tabular}

Fuente: elaboración propia

La duración de las entrevistas osciló entre veinte minutos y dos horas, como se especifica en la tabla 3. Aunque hubiese sido oportuno realizar entrevistas con más profundidad, en algunos casos no fue posible, puesto que se realizaron en horario laboral durante los breves periodos de descanso de las PDEP y de los/as profesionales del CATS.

Tabla 3. Duración de las entrevistas

\begin{tabular}{|l|l|}
\hline Duración de las entrevistas & N. $^{\circ}$ de entrevistas \\
\hline 20-35 minutos & 1 \\
\hline 35 minutos-1 hora & 5 \\
\hline 1 hora- 1 hora y media & 8 \\
\hline+ de 1 hora y media & 2 \\
\hline
\end{tabular}

Fuente: elaboración propia

Respecto al tipo de registro, todas las entrevistas se grabaron excepto una, dado el deseo expreso de la entrevistada, por lo que se tomaron notas durante la entrevista para su posterior reconstrucción (tabla 4). El trabajo de campo se realizó durante los meses de mayo y junio de 2019 en el municipio de Murcia y en zonas de prostitución de calle situadas en pedanías como Los Dolores o Puente Tocinos.

Tabla 4. Tipo de registro empleado en las entrevistas

\begin{tabular}{|l|l|}
\hline Tipo de registro & N. $^{\mathbf{o}}$ de entrevistas \\
\hline Grabadora & 15 \\
\hline Toma de notas y reconstrucción posterior & 1 \\
\hline
\end{tabular}

Fuente: elaboración propia

La estrecha colaboración del equipo del CATS en este estudio fue posible debido a que establecí mi primer contacto con la entidad hace seis años. Desde entonces, he formado parte del colectivo a través de diversas facetas: como voluntaria, como trabajadora sexual y como psicóloga investigadora. El hecho de haber participado en la entidad desde el año 2014 me ha permitido tener un amplio acercamiento a la realidad estudiada (mediante salidas a clubes de alterne, visitas a zonas de prostitución de calle, campañas de captación de fondos, participación en talleres de diversas temáticas, múltiples conversaciones con PDEP, asistencia a charlas y debates sobre trabajo sexual, etc.), lo que me posibilitó ser consciente de las múltiples violencias a las que están expuestas las personas que trabajan en prostitución, en especial las PDEP a las que atraviesan otras formas de opresión como puede ser el género, la orientación sexual, la nacionalidad, la etnia o la situación socioeconómica. 
Una vez contextualizado el ejercicio de la prostitución en la Región de Murcia, y especificada la metodología que se siguió durante el desarrollo del trabajo de campo, pasaremos a presentar brevemente el marco teórico que ha guiado esta investigación, para, posteriormente, exponer los resultados y las conclusiones.

\section{Marco Teórico: Violencias ejercidas hacia las personas que trabajan en la prostitución.}

Según la Organización Mundial de la Salud, la violencia es "el uso deliberado de la fuerza física o el poder, ya sea en grado de amenaza o efectivo, contra uno mismo, otra persona o un grupo o comunidad, que cause o tenga muchas probabilidades de causar lesiones, muerte, daños psicológicos, trastornos del desarrollo o privaciones" (OMS, 2002:3). En este sentido, Paula Arce (2018), abogada especializada en violencia de género y derechos humanos, declara que la principal violencia que señalan las PDEP es la violación habitual de sus derechos por parte de los clientes, la policía, los/as encargados/as de los clubes y los pisos de contactos y otras personas. Esta problemática también se refleja en las investigaciones en contextos de prostitución realizadas en España por la socióloga Laura Oso (2016), donde se demuestra que existen casos en los que las mujeres migrantes deciden trabajar en la industria del sexo no solo como una estrategia de supervivencia, sino también de movilidad social. Ahora bien, a pesar de la autodeterminación de emplearse en el comercio sexual, continúan siendo víctimas de los abusos y la explotación de terceras personas (Oso y Ulloa, 2001).

En diversos países se han llevado a cabo estudios que concluyen que las PDEP sufren una discriminación a nivel mundial que las hace susceptibles de padecer cualquier tipo de abuso (Arella, Fernández, Nicolás y Vartabedian, 2007). Esta tesis es confirmada por Amnistía Internacional (2016a, 2019), organización que afirma que las personas que ejercen el trabajo sexual se encuentran entre los grupos de población más marginados y violentados que existen. Por su parte, la filósofa Paula Sánchez (2018) enfatiza en la indefensión que sufren en caso de padecer violencia física, además de la violencia psicológica y simbólica anexa a la estigmatización. El Comité de Apoyo a las Trabajadoras del Sexo (2020) también destaca el estigma como el tipo de violencia percibida que frecuentemente expresan quienes ejercen la prostitución, el cual constituye la base para la discriminación, la negligencia y el maltrato hacia las prostitutas.

Un estigma es un atributo profundamente desacreditador del que existen tres tipos: deformidad física, defectos de carácter del individuo y características tribales (Goffman, 1970). Sin embargo, el rechazo no reside en el atributo (dedicarse al trabajo sexual), sino en la valoración negativa que la sociedad le asigna en un contexto determinado (Quiles, 2019). Las personas que ejercen la prostitución se enfrentan a un estigma de defectos de carácter del individuo, dado que son percibidas como desviadas, viciosas, ignorantes, indisciplinadas, enfermas mentales o malas madres (Garaizabal, 2007, 2008; Pheterson, 2000). Se debe agregar que algunas PDEP sufren doble estigmatización: en primer lugar, por dedicarse al trabajo sexual y, en segundo lugar, por aspectos tribales (pertenecer a otra etnia, país o religión). Mención especial merecen las/os trabajadoras/es del sexo trans, ya que además de ser estigmatizadas/os por su trabajo también lo son por su identidad (Sánchez, 2016); en este caso la estigmatización sería doble -y triple en el caso de ser extranjeras/os-. De igual modo, la estigmatización se intensifica en las/os trabajadoras/es con mayores necesidades económicas, en situación migratoria irregular (Juliano, 2005) o con edades avanzadas (Freixas y Juliano, 2008).

En algunos casos, el estigma asociado a la prostitución puede desembocar en violencias institucionales, siendo un claro ejemplo las protagonizadas por los cuerpos de seguridad del estado. Los abusos policiales han sido denunciados desde hace décadas. De hecho, el dos de junio se celebra 
el Día Internacional de las Trabajadoras del Sexo porque en el año 1975, en esa misma jornada, más de cien prostitutas ocuparon la iglesia Saint-Nizier en la localidad francesa de Lyon para llamar la atención sobre su mala situación y sobre las represalias continuas que sufrían por parte de la policía: abusos, multas y encarcelamientos (Colectivo Hetaira, 2011). Recientemente, la Agrupación Feminista de Trabajadoras del Sexo -AFEMTRAS- y el Colectivo Hetaira, denunciaron insultos y vejaciones por parte de varios agentes policiales de la Unidad contra Redes de Inmigración llegal y Falsedades Documentales (UCRIF) a las prostitutas que trabajan en el polígono industrial Marconi, en Villaverde (Madrid). Algunos agentes de la UCRIF se dirigían así a las PDEP: "Vete a zorrear a tu país". "Con Franco esto no pasaría". "Os voy a llevar a presas". "A limpiar escaleras". "Te voy a pegar dos hostias" (Colectivo Hetaira, 2016). En este sentido, también se pronuncia Amnistía Internacional (2016b, 2019), sosteniendo que la criminalización mediática de las trabajadoras sexuales, combinada con el profundo machismo, alimenta las detenciones arbitrarias a manos de la policía y permite que estas violaciones de derechos humanos se cometan impunemente.

Asimismo, otra muestra de violencia en las instituciones es la que se produce en los servicios sociales y en la sanidad pública. Por ejemplo, en un estudio etnográfico desarrollado en la provincia de Almería (España), la antropóloga Estefanía Acién (2014) mostró la discriminación que acontecía hacia las PDEP en los servicios públicos a través de algunos/as funcionarios/as. Hay que mencionar, además, que las conductas estigmatizantes en los sistemas de salud hacia las personas trabajadoras del sexo pueden desembocar en que decidan automedicarse o acudir a consultas privadas (The Global Network of Sex Work Projects, NSWP, 2017). Otro aspecto relevante es como desde los sistemas sanitarios todavía se señala a las personas que ejercen la prostitución como grupo de riesgo en el contagio de infecciones de transmisión sexual (Acién, 2015; Amaya, Canaval y Viáfara, 2005; CATS, 2017b). Este hecho ocasiona que se dejen en segundo lugar otras cuestiones de salud no relacionadas con las ITS.

También podemos considerar como una forma de violencia las acciones contra la prostitución que están desarrollando asociaciones nacionales e internacionales, las cuales reproducen la estigmatización de las PDEP. Una muestra es la campaña "Yo no soy putero", realizada en el 2018 por Médicos del Mundo con la colaboración del Gobierno de Aragón (imagen 1). Aunque se pretende poner el foco en la clientela, mediante esta campaña se está victimizando y homogeneizando a las PDEP, puesto que se utilizan los conceptos "trata" y "prostitución" de forma intercambiable. A su vez, con la afirmación "sin prostitución no hay trata", se responsabiliza a las personas que deciden ocuparse en la industria del sexo de la trata de personas, cuando lo oportuno sería abordar las auténticas causas como, por ejemplo, las políticas migratorias restrictivas o la precariedad laboral. La antropóloga Laura María Agustín (2009), aborda ampliamente esta cuestión en su libro "Sexo y marginalidad. Emigración, mercado de trabajo e industria del rescate", en el que expone cómo las ONG se lucran a partir de la criminalización de la industria del sexo. De forma análoga se pronuncia el abogado y sociólogo José López-Riopedre, considerando que las políticas punitivas con la prostitución alimentan al tercer sector, siendo los/as responsables de estas ONG quienes obtienen beneficios y no tanto las PDEP, a "quienes ahogan en su propio itinerario victimizador" (2011:13). 


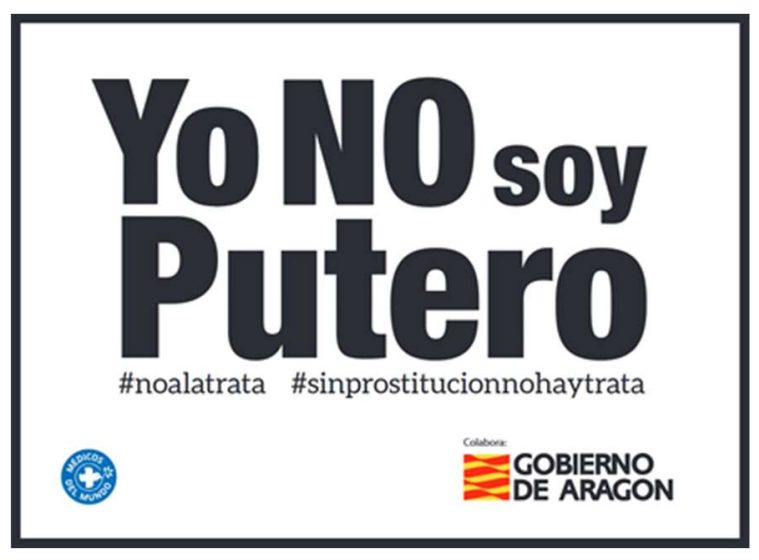

Fuente: Médicos del Mundo, (2018).

Por otro lado, tal y como se menciona en la introducción, los dos colectivos de agresores/as más estudiados en las investigaciones sobre prostitución son la clientela y el empresariado de los clubes de alterne y los pisos de contactos. En el caso de la clientela, siguiendo a López-Riopedre (2012), podemos destacar que los hombres consumidores de servicios sexuales son un reflejo de la sociedad, de ahí que existan clientes misóginos que protagonizan conductas violentas y/o delictivas sobre las trabajadoras del sexo, tales como no respetar las condiciones pactadas intentando realizar prácticas que en la negociación se acordó que no se efectuarían. En cuanto al empresariado de la industria del sexo diversos estudios recalcan las condiciones de trabajo muy precarias a las que las PDEP están sometidas, tanto respecto a su explotación como trabajadoras, como respecto a su salud y seguridad en el ámbito laboral (Bindman, 1997, citado en Arella et al., 2007). Asimismo, el empresariado se aprovecha de la desprotección legal para sacar grandes beneficios a costa de las PDEP a través de múltiples vías: alquiler de habitaciones; el porcentaje que reciben de los servicios sexuales y la copas; las cuotas diarias y los elevados suplementos que las trabajadoras pagan por la comida, las toallas, las sábanas o los preservativos; las multas impuestas a las PDEP que permanecen mucho tiempo en su cuarto sin salir a trabajar, etcétera (Oso, 2008; 2005). Como apuntó la trabajadora sexual y activista Nereida Lakuló (2007), en la obra colectiva "La prostitución a debate. Por los derechos de las prostitutas" (Briz y Garaizabal, 2007), es imprescindible que las propuestas políticas se centren en los intereses de todas las personas implicadas en la prostitución y no solo en el beneficio de los grandes grupos de empresarios que obvian los derechos y los intereses de los y las trabajadoras del sexo.

Por último, mencionaremos brevemente algunos de los hallazgos respecto a la violencia protagonizada por secciones del feminismo. Violencia que en los últimos años ha adquirido protagonismo, sobre todo a raíz de las campañas de acoso y difamación en redes sociales hacia trabajadoras/es del sexo politizadas/os. En este sentido, la antropóloga Isabel Holgado (2008) considera que las tácticas utilizadas para legitimar su discurso por algunas feministas antiprostitución se pueden equiparar a las herramientas usadas por el patriarcado: negación de la capacidad de agencia, tergiversación de la información, infantilización (Doezema, 2004), psicopatologización vinculada al hecho de ejercer la prostitución, oposición a dialogar con PDEP por considerarlas aliadas del sistema patriarcal, etcétera (Osborne, 2004; 2007).

A continuación, se expondrán los principales resultados del trabajo de campo en la Región de Murcia. El estigma asociado a la prostitución constituye la base de otras violencias tales como la discriminación, el discurso de odio o el maltrato institucional. Por tanto, en primer lugar, se abordará el estigma puta. Los siguientes subapartados se corresponden con algunas de las violencias ejercidas hacia las PDEP por diferentes colectivos: profesionales sanitarios/as, trabajadores/as de los servicios 
sociales, políticos/as, cuerpos de seguridad estatal, entidades del tercer sector, secciones feministas, empresariado de la industria del sexo, clientela, investigadores/as vinculados a la academia, medios de comunicación, familiares, parejas, exparejas, amistades y otros/as responsables.

\title{
4 Resultados
}

\subsection{El estigma asociado a la prostitución: la mayor violencia y de la que todas/os somos responsables}

La psicóloga Cristina Garaizabal (2007) afirma que lo que mayoritariamente genera las malas vivencias, la angustia o la baja autoestima, no son tanto las prácticas sexuales que se desarrollan en el trabajo sexual, sino la falta de derechos laborales y la devaluación social. Los resultados de esta investigación son coincidentes, ya que prácticamente la totalidad de las personas entrevistadas señalaron que lo que más perjudicaba a las PDEP era tener que llevar una doble vida a raíz del estigma. En cuanto a lo que supone, podemos hablar de un intenso temor ante la idea de que pueda trascender la vida oculta en la vida pública, por lo que las personas que ejercen la prostitución en secreto se ven sometidas a un continuo estado de alerta.

"Lo que más pesa de alguna manera como una violencia es el estigma social. Es lo que transmiten
como mayor problema, más allá de la lucha económica vinculada al proyecto migratorio (...). En
el estigma social todos somos responsables, porque es una construcción social que forma parte
de las diferentes mentalidades que componen esa sociedad. Entonces, en el estigma social todos
y todas podemos hacer algo: o incrementarlo o reducirlo" (Educadora social, PR.3)

Uno de los casos de miedo al rechazo y de ocultación del ejercicio de la prostitución es el de TS.9. Esta mujer española de veintisiete años comenzó a ejercer la prostitución cuando se mudó a Barcelona (España) en el 2017. Al cambiar de ciudad se sentía sola, y como le había supuesto mucho esfuerzo hacer amistades no quería perderlas. Por ende, tuvo que ocultar su trabajo tanto en la nueva ciudad de residencia, como ante su familia y las amistades que se encontraban en Murcia.

\begin{abstract}
"Viendo cómo habían reaccionado de mal cuando les conté que me prostituía, tanto mi gente cercana como mis compañeras de piso, pues me daba miedo que las pocas amistades que había hecho me rechazaran, y con lo que me ha costado... pues me callé" (Trabajadora sexual española, TS.9)
\end{abstract}

Otro testimonio muy relevante respecto a las múltiples consecuencias que conlleva el estigma nos lo compartió TS.6, una mujer peruana de treinta y cinco años con dos hijas a cargo. Esta trabajadora del sexo, a pesar de que tiene muy presentes los beneficios que le proporciona ejercer la prostitución (mayores ingresos, facilidad en la conciliación, disfrute de diversidad de experiencias sexuales, etc.), considera que ha tenido que pagar un alto precio a nivel emocional debido al repudio asociado a su trabajo.

\footnotetext{
“iA mí me parece el mejor trabajo del planeta! Por lo menos pa'mí. A lo mejor porque yo puedo elegir (...). Tía, yo no puedo explicar lo bondadosa, lo generosa, lo noble... la experiencia que yo he tenido en la prostitución me ha empoderado sexual y económicamente, porque es muy muy rentable" (Trabajadora sexual peruana, TS.6)

“Es un miedo perpetuo. El tener que estar ocultándoselo a mi familia es terrible. Yo sinceramente pienso que esa es la peor parte de la prostitución. La doble vida es lo peor. No sé... esa es la peor parte, la de no salir del closet [llora y le cuesta hablar] (...). En la prostitución el precio es tu libertad emocional. El precio aquí es tener una doble vida si no vas a salir del armario. Y si sales del armario el precio es aprender a vivir con el estigma. Todo tiene un precio finalmente" (Trabajadora sexual peruana, TS.6)
} 


\subsection{Miedos y mentiras durante las visitas a los servicios sociales y a los centros de salud}

Algunas de las PDEP participantes evitaban acudir a los servicios sociales porque anticipaban posibles conductas discriminatorias de los/as trabajadoras/es sociales por motivos relacionados con su trabajo, como la retirada de la custodia de sus hijos/as. Ahora bien, cuando decidían asistir a los servicios sociales o a los servicios de la sanidad pública la mayoría ocultaba que se dedicaba a la prostitución, con la finalidad de protegerse de juicios y/o episodios de maltrato como el sufrido por TS.4:

"Una vez tuve una muy mala experiencia con un digestivo, porque yo he tenido siempre problemas del estómago, entonces yo le conté al médico de que yo ejercía la prostitución y me dijo: "ya ves los problemas que usted se acarrea por andar en esas sinvergonzonerías". Entonces yo me cabreé y le dije: “¿pero usted que tiene que opinar de mi vida personal?". Después, me levanté de la silla y me fui" (Trabajador sexual ecuatoriano, TS.4)

Situaciones como la vivida por TS.4 ocasionan importantes perjuicios, en vista de que para ciertas problemáticas relacionadas con la salud sería oportuno que las PDEP pudieran hablar con naturalidad de su ocupación. Es, por ejemplo, el caso de las revisiones ginecológicas y andrológicas. Por otro lado, aunque algunos/as entrevistadas/os afirmaron acudir a doctores/as privados/as o a la consulta ginecológica del CATS no podemos conformarnos con este hecho, debido a que no todas las PDEP pueden permitirse pagar la sanidad privada o asistir a la consulta ginecológica del CATS por motivos relacionados con la movilidad laboral.

Con respecto a la salud psicológica, varias de las personas entrevistadas declararon que los/as profesionales sanitarios/as habían relacionado sus problemas de salud mental con el trabajo sexual, por lo que la solución principal que aportaban pasaba por abandonar la prostitución. Es decir, en primera instancia se producía una problematización del trabajo sexual, y los/as profesionales de la psiquiatría y/o la psicología no indagaban en el conjunto de causas que pudieran estar afectando al bienestar psicológico de la persona.

"Sobre todo, me he sentido violentada por profesionales de la salud mental. Hicieron una lectura del tema [trabajar en prostitución] como si me estuviera autodestruyendo, lo psicopatologizaron mucho. Pues cosas de mi vida que no tenían que ver con la prostitución enseguida las relacionaron con prostitución. Con lo cual tampoco estaban yendo a la diana correcta. A raíz de haber sido prostituta psicopatologizaron mucho mi sexualidad, porque consideraban que no era lo suficientemente íntima, monógama, emocional, etcétera. Que no estaba lo suficientemente sujeta a la heteronormatividad y al proyecto de tener una relación de pareja estable con alguien." (Trabajadora sexual española, TS.1)

\subsection{Elaboración e implementación de leyes: todo por las prostitutas, pero sin las prostitutas}

La combinación de política abolicionista en materia de trabajo sexual y política migratoria restrictiva limita, en gran medida, la posibilidad de que las PDEP, en especial las migrantes, puedan acceder a derechos civiles y laborales (Oso, 2008). Por otra parte, es reseñable cómo en España los poderes políticos están desoyendo la voz de las trabajadoras del sexo e impidiendo que participen como interlocutoras válidas en la elaboración de las legislaciones que les atañen (Arella et al. 2007). En este sentido, dos de las PDEP entrevistadas resaltaron cómo habían sido ignoradas cuando habían intentado iniciar diálogos con representantes políticos, concretamente se refirieron a miembros del PSOE (Partido Socialista Obrero Español) a nivel regional y estatal.

"Incluso en estas elecciones [elecciones generales de España del 28 de abril de 2019] por más que se insistió en que nos invitaran a los debates, el gobierno se declaró abolicionista, pero sin nunca consultar a las trabajadoras sexuales. Está claro que no estamos dentro de la agenda, ni del feminismo, ni de la política" (Trabajadora sexual mexicana, TS.3) 
Por otro lado, los/as profesionales del tercer sector manifestaron que por lo que se sienten más violentadas las mujeres que captan a la clientela en la calle es por la ordenanza para luchar contra la prostitución del municipio de Murcia y por la Ley Orgánica 4/2015 de protección de la seguridad ciudadana. Aunque mediante la ordenanza se aduce perseguir la igualdad, se está produciendo un aumento de las desigualdades entre las trabajadoras del sexo que ejercen en la vía pública y el resto de la población.

\begin{abstract}
"Ellas se encuentran en una situación de una continua ansiedad y de tener miedo a salir de su casa (...). A las mujeres les causa mucha desazón, porque ellas temen que esa multa les vaya a perjudicar a la hora de sacar sus papeles de residencia que están en trámite, que los tienen que renovar o que se van a iniciar. Eso las victimiza mucho más, por lo que no se aplica la perspectiva de género de la ordenanza." (Abogada, PR.6)
\end{abstract}

\title{
4.4 Garantes de la seguridad: multas y persecuciones a la hora de comprar el pan
}

Los/as profesionales del CATS destacaron que durante los primeros meses de la ordenanza antiprostitución las mujeres que captan a su clientela en el Barrio del Carmen se vieron muy acosadas, ya que son vecinas de la zona conocidas por la policía. A raíz de la ordenanza, los/as agentes comenzaron a poner multas a estas trabajadoras cuando salían a comprar, a recoger a sus hijos/as del colegio o cuando estaban paseando. Además, la policía comenzó a realizar sus labores de paisano, con lo que se les vulnera mucho más, porque ya ni siquiera pueden identificar quién es policía y quién no, lo que hace que todavía tengan más miedo. Asimismo, algunas mujeres no pueden pagar las multas, lo cual hace más difícil su ya delicada situación socioeconómica. Es importante destacar que en el Barrio del Carmen las trabajadoras del sexo no se ocupan en la vía pública, sino que captan a la clientela en la calle y prestan sus servicios en pisos.

"Lo resultante de la ordenanza para luchar contra la prostitución es una angustia vital total, o sea, las repercusiones son bestiales. Y eso es de lo que no se da cuenta la gente, el cómo puede afectar a una persona el hecho de tener miedo a bajar a comprar el pan (...). La policía local multa muchísimas veces sin seguir el texto de la ordenanza. $O$ sea, ya tienen nombre y apellidos de las mujeres. $O$ sea, son cuarenta y pico mujeres que se sabe quiénes son y en cuanto bajan de la casa pues las multan, porque saben que son trabajadoras del sexo, cuando ni siquiera están captando un cliente." (Coordinador, PR1)

Por otro lado, a lo largo de las entrevistas se compartieron testimonios que relataban abusos sexuales por parte de miembros de la policía que se aprovechaban de su posición de poder, sobre todo ante trabajadoras/es del sexo migrantes en situación administrativa irregular.
"A veces, los policías venían de paisano a la barra y toqueteaban a las chicas, sobre todo a las nuevas. Ellas, como tenían miedo de que las deportaran, se dejaban tocar." (Trabajadora sexual brasileña, TS.8)
“Cuando llegué a España y empecé a prostituirme había un patrullero que se pasaba por la zona dónde yo captaba la clientela. En esa época yo no tenía los papeles y los policías me decían que si no me iba con ellos y se la chupaba me iban a llevar al calabozo (...). Tuve que irme con ellos varias veces en el coche y hacerles lo que me pidieran." (Trabajador sexual ecuatoriano, TS.4)

\subsection{Entidades del tercer sector: del empoderamiento al paternalismo}

Las personas entrevistadas afirmaron que el juicio por ser trabajadora sexual existe desde el momento en que lo primero que te ofrecen algunas ONG es una alternativa laboral, antes siquiera de escuchar las demandas de la persona a la que están atendiendo. A lo largo del trabajo de campo se pudo constatar que el principal inconveniente de los recursos ofrecidos por algunas entidades es su carácter discriminatorio, ya que tratan a las personas que ejercen la prostitución como ignorantes, vulnerables e indisciplinadas. Como resultado, la movilidad laboral de las PDEP se dificulta por la idea transmitida de que hay que reeducarlas en habilidades básicas antes de que 
puedan desempeñar otras tareas diferentes a la prostitución (Juliano, 2002). Por tanto, unos recursos de orientación laboral inapropiados, unidos al rechazo social y a la escasez de empleo, provocan que la inclusión de las PDEP en el mercado laboral reglado de la Región de Murcia se convierta en un objetivo realmente complejo. Así, por ejemplo, una de las trabajadoras sexuales entrevistadas (TS.1) se mostró disgustada tras acudir a Cáritas y preguntar por proyectos dirigidos a trabajadoras sexuales. El motivo fue que le mostraron un programa en el que se les enseñaba a las PDEP a actividades tan elementales como el lavado de la ropa. A pesar de que existen personas que necesitan de este tipo de recursos, resulta inapropiado que se oferten al colectivo de trabajadoras sexuales de forma genérica.

"Fui a Cáritas, y la monja que me atendió me estuvo explicando un montón de programas que tenían y, entre ellos, había un programa para prostitutas en el que les enseñaban a lavar la ropa, a planchar, a cuidar de sus hijos y de vez en cuando las llevaban de excursión al museo. Y yo le dije: "bueno, es que el hecho de que sean prostitutas no significa que no sepan hacer todas esas cosas." (Trabajadora sexual española, TS.1)

Además, trabajadoras del sexo politizadas sienten que incluso desde las ONG pro-derechos muestran reticencias a la hora de que se autoorganicen, debido a que temen que las PDEP logren un empoderamiento tan sublime que ya no las necesiten, lo que podría desembocar en el cierre de estas entidades y en la pérdida de los empleos vinculados.

"Lo que yo siento, todavía, por parte de las asociaciones pro-derechos es que hay un tutelaje. Todavía no hay espacio para que nosotras tomemos nuestras propias decisiones o nos organicemos, y que las propias organizaciones nos apoyen al 100\% sin cuestionar lo que estamos haciendo." (Trabajadora sexual mexicana, TS.3)

"Las ONG chupan del bote y eso sí me violenta mucho (...). A mí me parece muy fuerte que la gente de las asociaciones tenga 14 pagas al año y yo no llegue a fin de mes." (Trabajadora sexual mexicana, TS.3).

\section{6 "Toda mujer tiene derecho a decidir, mientras no decida ser prostituta". Feminismos y negación de la capacidad de agencia}

Dentro de los feminismos la prostitución se entiende de diversos modos, dando lugar a que unos sectores batallen junto a las trabajadoras del sexo por la conquista de sus derechos, mientras que otros defienden una postura abolicionista/prohibicionista de la prostitución violentando, en ocasiones, al colectivo de mujeres al que afirman proteger. Durante las entrevistas, algunas de las trabajadoras del sexo participantes expresaron que sienten que desde el feminismo más institucionalizado solo hablan de los efectos del patriarcado y el capitalismo en su profesión, como si en las demás no estuviera presente.

"Estar trabajando, como yo, 25 horas a la semana en un restaurante por 500 euros no es ser una esclava del patriarcado ni del capitalismo, ¿̇verdad?" (Trabajadora sexual española, TS.9)

Por otra parte, en debates y conferencias sobre prostitución se ha producido la negación de los discursos de activistas pro-derechos, debido a que no encajan en el molde del discurso demonizador de la industria del sexo propio del feminismo abolicionista. Asimismo, entidades pro-derechos como el CATS han sido tildadas de proxenetas, mientras que las trabajadoras del sexo politizadas han sido tachadas de malas mujeres al no aceptar el estatus de víctima. El resultado es que muchas PDEP sientan un profundo malestar a la hora de participar en eventos relacionados con los feminismos, como le ocurrió a TS.6 cuando participó en la manifestación del Día Internacional de la Mujer del 8 de marzo del año 2019.

“Cuando yo fui a la manifestación del 8M fui asustadísima, fui con una máscara porque me di cuenta de que la necesitaba (...). Además, yo me sentía muy violentada porque yo no sabía qué personas y qué sector del $8 \mathrm{M}$ era el que me apoyaba (...). Hay un colectivo de mujeres, además 
inmenso, que tiene unos mensajes de odio que lo único que hacen es asustarte de verdad. Yo tenía un montón de miedo en el 8M." (Trabajadora sexual peruana, TS.6)

\subsection{El empresariado de la industria del sexo: el summum de la vulneración de derechos}

En el análisis de los datos extraídos se ha mostrado cómo en los clubes de la Región de Murcia se vulneran múltiples derechos laborales: las jornadas de trabajo suelen ser de más de 12 horas; no disponen de vacaciones ni de días libres; el porcentaje de la ganancia en la venta de las copas es cada vez más bajo; los/as empresarios/as dan de alta a las trabajadoras como camareras, pero ellas tienen que pagarse la seguridad social, etc. Por otro lado, las PDEP afirman que el mayor abuso que se comete en los pisos de contactos es que se llevan porcentajes muy altos de su trabajo: al menos del $50 \%$. Además, los empresarios/as de la industria del sexo, en ocasiones, intentan imponer prácticas sexuales y formas de trabajar con las que las PDEP no están de acuerdo.

"Ha habido sitios en los que me han echado del trabajo por no complacer al cliente $100 \%$ como los jefes querían que lo hiciera. Me dejaron dinero sin pagar e intentaban imponerme prácticas como sexo sin condón o sexo anal, pero mis apetencias van primero." (Trabajadora sexual brasileña, TS.8).

\subsection{La clientela: dar poco y pedir mucho}

Durante el trabajo de campo todas las PDEP se quejaron de que algunos de sus clientes no respetan su trabajo, e intentan regatearles las tarifas para disfrutar de extensos servicios (con todo tipo de prácticas) por muy poco dinero. Por otro lado, tampoco se sienten respetadas cuando clientes con los que acuerdan un servicio no acuden a la cita y no llaman para cancelarla (situación que se torna muy habitual). En este sentido, una de las trabajadoras entrevistadas, aunque piensa que la prostitución es un buen trabajo para ella porque le permite conciliar con su faceta de madre y esposa, en varias ocasiones destacó la falta de consideración de los clientes.

"Igual que todo trabajo, tiene unos costes y unos beneficios, y ellos se piensan que solo tenemos beneficios. No lo paran a pensar y, a veces, solo te ven como un objeto al que follar." (Trabajadora sexual española, TS.2).

Asimismo, existe un sector minoritario de clientes que abusa sexualmente de las PDEP o intenta chantajearlas para recibir servicios gratis. Cómo comentan desde el CATS, estos comportamientos violentos pueden afectar gravemente en a la salud física y psicológica.

"Hay un sector de clientes que no trata bien a las trabajadoras sexuales y hay algunas a las que le afecta en su propia autoestima. Hablando de violencias y de clientes... estaba pensando en los clientes que se rompen el preservativo. Que por cierto salió hace poco una sentencia en la que, efectivamente, se considera abuso sexual el romper un preservativo o quitarlo cuando se ha acordado una práctica sexual con preservativo (...). Las chicas me cuentan que les pasa, aunque no frecuentemente." (Ginecóloga, PR.2).

Otra violencia que mencionaron algunas de las personas entrevistadas se refiere a los clientes que acuden a solicitar los servicios de las trabajadoras del sexo con falta de higiene, ya que piensan que por el hecho de pagar todo está permitido.

"Como van a pagar vienen todo mugrosos después de estar todo el día trabajando. Como van a pagar su mierda de 15 o 20 euros vienen todo cochinos a que les chupes la polla." (Trabajadora sexual ecuatoriana, TS.5).

\subsection{Profesionales de los medios de comunicación y de la academia: a la caza del morbo}

Los medios de comunicación y las investigaciones académicas, en algunos casos, avivan el estigma asociado a la prostitución, ya que suelen mostrar a PDEP que presentan características como el consumo de drogas, enfermedades de transmisión sexual, problemas de salud mental o conductas delictivas. Durante los encuentros, las PDEP y los profesionales del CATS aludieron a la importancia 
que los medios de comunicación tienen en la construcción de las imágenes sesgadas sobre las PDEP. Destacan que existe la necesidad de desactivar la carga estigmatizadora que se da en el tratamiento sensacionalista del trabajo sexual, porque se tiende a mostrar una imagen de las/os prostitutas/os asociada con la delincuencia, la drogadicción y la desviación. Asimismo, las PDEP entrevistadas se sienten ignoradas en el desarrollo de investigaciones y debates que tienen que ver con su trabajo.

"Que escuchen a las mujeres trabajadoras. Que nos escuchen. Solo pedimos eso. Que si quieren hacer algún estudio que nadie hable por nosotras. No necesitamos que nadie hable por nosotras. Si hacen algún estudio que nos tomen en cuenta." (Trabajadora sexual ecuatoriana, TS.5).

\subsection{Otros/as responsables, otras violencias}

"Yo procuro que lo que hago con una mano no se entere la otra mano. Me da mucha vergüenza y mucho respeto porque tengo familia (...). Si se entera mi familia me quitan hasta el apellido." (Trabajadora sexual española, TS.7).

En el caso de TS.7, en principio, no podríamos hablar de violencia intrafamiliar que se haya materializado, pero sí de una anticipación al rechazo, lo que desemboca en una profunda autovigilancia y estrés. Esta trabajadora vivía ejercer la prostitución con gran angustia, y destacaba que para ella era una actividad temporal que solo realizaba cuando se encontraba en fuertes apuros económicos. También, se dan situaciones de ocultamiento a parejas y exparejas, sobre todo si hay hijos/as por medio. Y es que el hecho de ejercer la prostitución en manos de padres maltratadores puede utilizarse como chantaje y como una amenaza para la retirada de custodia.

"A partir de que mi exmarido empezó a sospechar que era prostituta fue un acoso constante y a perpetuidad. Tía, no he pasado mayor ansiedad en mi vida, al verle la cara y pensar que iba a agredirme." (Trabajadora sexual peruana, TS.6).

Habría que mencionar, además, testimonios de PDEP que debido a su trabajo han tenido problemas de convivencia con compañeras/os de piso y con vecinos/os. Personas con los/as que mantenían una buena relación hasta que salió a la luz que se dedicaban a la prostitución.

\footnotetext{
"Una vez estuve en un piso de alquiler en el que me pusieron hasta cámaras de vigilancia en el pasillo para ver si entraban clientes a mi casa. Tuve enfrentamientos muy grandes con mis vecinos y con mi casero porque estaban vulnerando mi privacidad (...). Yo no entendía tanto revuelo, porque yo sobre todo trabajaba en la calle y a mi piso solo entraban unos pocos clientes de confianza." (Trabajadora sexual ecuatoriana, TS.5).
}

Como hemos podido comprobar a lo largo de estos diez sub apartados la violencia hacia las PDEP está caracterizada por su complejidad, tanto a nivel de la naturaleza de las agresiones (físicas, psicológicas, sexuales...), como de las/os agentes sociales responsables (cuerpos de seguridad estatal, trabajadoras/es sociales, periodistas...), lo que inserta a las PDEP en un clima de inseguridad ya que, por el hecho de ejercer la prostitución, en ocasiones, no se sienten respaldadas ni por sus redes sociales más íntimas.

\section{Conclusiones}

En el presente estudio el objetivo fundamental ha consistido en visibilizar a los colectivos que ejercen violencias hacia las PDEP, con el fin de situar el foco en las personas estigmatizadoras y responsables de las agresiones, y no tanto en el colectivo estigmatizado: las personas que trabajan en la prostitución. Para ello, se ha abordado desde la violencia física y sexual a la relacionada con la vulneración de derechos humanos, pasando por la vinculada al despojo de la capacidad de agencia mediante la victimización de las PDEP. Como se mencionó con anterioridad, la hipótesis de partida es que las condiciones laborales, la salud y las relaciones interpersonales de las PDEP están determinadas por la articulación de una cadena de violencias ejercidas por diferentes agentes sociales. Dicha hipótesis se ha confirmado, ya que las múltiples violencias abordadas a lo largo del 
texto no resultan inocuas. El resultado es la exclusión, una forma de violencia estructural que se deriva de las circunstancias del sistema; se trata de un recorrido social a través del cual las personas pierden progresivamente los vínculos que les unen con la sociedad. En este proceso existen factores desencadenantes que se acumulan, y combinan desventajas en los diferentes ámbitos de la vida de las PDEP (Tezanos, 1999).

Por otra parte, la principal violencia que perjudica a las PDEP y que supone el caldo de cultivo de gran parte de las restantes formas de violencia es el estigma de puta ${ }^{4}$. El rechazo social fruto del estigma se materializa en que algunos/as miembros de los cuerpos de seguridad del estado comentan abusos de poder; en que referentes feministas difamen y silencien a las PDEP; en que las ONG sientan que pueden llevar las riendas de la vida de las PDEP, a las que consideran víctimas carentes de autodeterminación; o en que la academia y los medios de comunicación busquen acumular audiencias y logros a partir del sensacionalismo con el que abordan las vidas y las realidades de las personas que ejercen la prostitución. Para sintetizar los resultados fruto del análisis de las entrevistas podemos observar la tabla 5: una herramienta analítica que identifica el estigma como eje vertebrador de las violencias, así como a los actores y a las actrices que las protagonizan.

En cuanto a las limitaciones de este estudio, destacaría que la accesibilidad al colectivo de trabajadoras/es del sexo que ejercen o han ejercido en la Región de Murcia ha sido compleja debido a la movilidad del colectivo y a la clandestinidad en la que muchas/os ejercen su trabajo. Por ende, la muestra de personas entrevistadas no es representativa y los resultados obtenidos no pretenden ser generalizables. No obstante, se considera que esta aproximación a las violencias que sufren las PDEP puede servir como punto de partida para realizar investigaciones más profundas en el territorio murciano, y para desarrollar estrategias en dos sentidos: en primer lugar, para prevenir las violencias mediante la realización de intervenciones con los actores y actrices que las ejercen y, en segundo lugar, para el diseño de programas destinados a apoyar a las PDEP que lo necesiten en el afrontamiento de estas agresiones.

Tabla 5.

Violencias ejercidas hacia las personas que ejercen la prostitución en la Región de Murcia: clasificación según colectivos responsables

\begin{tabular}{|c|c|c|}
\hline $\begin{array}{c}\text { Eje } \\
\text { vertebrador }\end{array}$ & $\begin{array}{c}\text { Violencias } \\
\text { según actores/ } \\
\text { actrices }\end{array}$ & Características principales \\
\hline $\begin{array}{l}\text { El estigma } \\
\text { puta }\end{array}$ & $\begin{array}{l}\text { Profesionales } \\
\text { de los servicios } \\
\text { sociales y del } \\
\text { sistema } \\
\text { público de } \\
\text { salud }\end{array}$ & $\begin{array}{l}\text { - Retiradas de custodia motivadas por el ejercicio de la } \\
\text { prostitución. } \\
\text { - Denegación de ayudas económicas. } \\
\text { - Consideración de las PDEP como un grupo de riesgo para } \\
\text { el contagio de ITS. } \\
\text { - Psicopatologización de la prostitución. }\end{array}$ \\
\hline
\end{tabular}

${ }^{4}$ La antropóloga Dolores Juliano (2002) define el estigma puta como un proceso de construcción de un marco interpretativo con representaciones negativas sobre las PDEP, lo que condicionan el trato que reciben posteriormente por parte de la sociedad. Según la antropóloga, las representaciones oscilan entre considerarlas esclavas modernas o, por el contrario, mujeres que lo hacen motivadas por el placer sexual y el dinero. No obstante, la realidad es que la mayoría de las PDEP están situadas en un punto intermedio del continuo que va desde la prostitución forzada a la vocacional (Sanchís, 2011).

Revista del Laboratorio Iberoamericano para el Estudio

Sociohistórico de las Sexualidades https://doi.org/10.46661/relies.5062 


\begin{tabular}{|c|c|}
\hline & $\begin{array}{l}\text { - Consideración de la prostitución como la causa de } \\
\text { enfermedades físicas que tienen otro origen. }\end{array}$ \\
\hline Políticos/as & $\begin{array}{l}\text { - Desprotección resultante de la ausencia de legislación } \\
\text { laboral. } \\
\text { - Inacción ante las demandas y las necesidades básicas de } \\
\text { las PDEP. } \\
\text { - Negativa a entablar diálogos con colectivos de } \\
\text { trabajadoras/es del sexo. } \\
\text { - Medidas punitivas: } \\
\text { O Ordenanza para luchar contra la prostitución del } \\
\quad \text { Municipio de Murcia. } \\
\text { - Ley de seguridad ciudadana. } \\
\text { - Campañas antitrata y antiprostitución estigmatizantes. }\end{array}$ \\
\hline $\begin{array}{l}\text { Cuerpos de } \\
\text { seguridad del } \\
\text { estado }\end{array}$ & $\begin{array}{l}\text { - Abuso de poder. } \\
\text { - Abusos sexuales y violaciones. } \\
\text { - Persecuciones y hostigamiento. } \\
\text { - Multas y detenciones arbitrarias. } \\
\text { - Inactividad ante denuncias de las PDEP a clientes. }\end{array}$ \\
\hline $\begin{array}{l}\text { Entidades del } \\
\text { tercer sector }\end{array}$ & $\begin{array}{l}\text { - Victimización y revictimización. } \\
\text { - Paternalismo y tutelaje. } \\
\text { - Lucro a partir de la victimización de las PDEP. } \\
\text { - Problematización del ejercicio de la prostitución. } \\
\text { - Presiones para dejar el trabajo sexual. } \\
\text { - Recursos discriminatorios de orientación laboral. } \\
\text { - Campañas y acciones antiprostitución estigmatizantes. }\end{array}$ \\
\hline $\begin{array}{l}\text { Secciones } \\
\text { feministas }\end{array}$ & $\begin{array}{l}\text { - Discurso de odio. } \\
\text { - Victimización y negación de la capacidad de agencia. } \\
\text { - Lucro a partir de la victimización de las PDEP. } \\
\text { - Exclusión de las PDEP de espacios feministas. } \\
\text { - Tergiversación y deslegitimación de discursos. }\end{array}$ \\
\hline
\end{tabular}
https://doi.org/10.46661/relies.5062 


\begin{tabular}{|c|c|}
\hline & $\begin{array}{l}\text { - Acusación de proxenetismo a PDEP y a entidades aliadas. } \\
\text { - Reproducción del estigma puta. }\end{array}$ \\
\hline $\begin{array}{l}\text { Empresariado } \\
\text { de la industria } \\
\text { del sexo }\end{array}$ & 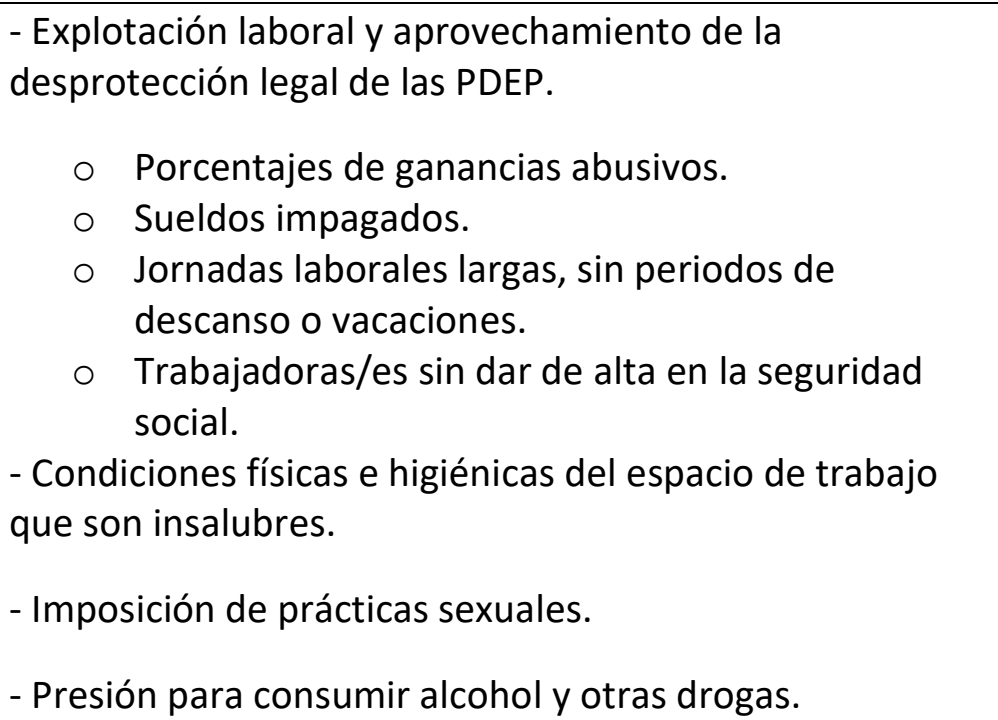 \\
\hline Clientela & $\begin{array}{l}\text { - Incumplimiento de las prácticas y condiciones pactadas. } \\
\text { - Amenazas y chantajes. } \\
\text { - Abuso sexual y violación. } \\
\text { - Falta de higiene. } \\
\text { - Presión para consumir drogas. } \\
\text { - Insultos, desprecio y misoginia. } \\
\text { - Plantones habituales. }\end{array}$ \\
\hline $\begin{array}{l}\text { Profesionales } \\
\text { de los medios } \\
\text { de } \\
\text { comunicación } \\
\text { y academia }\end{array}$ & 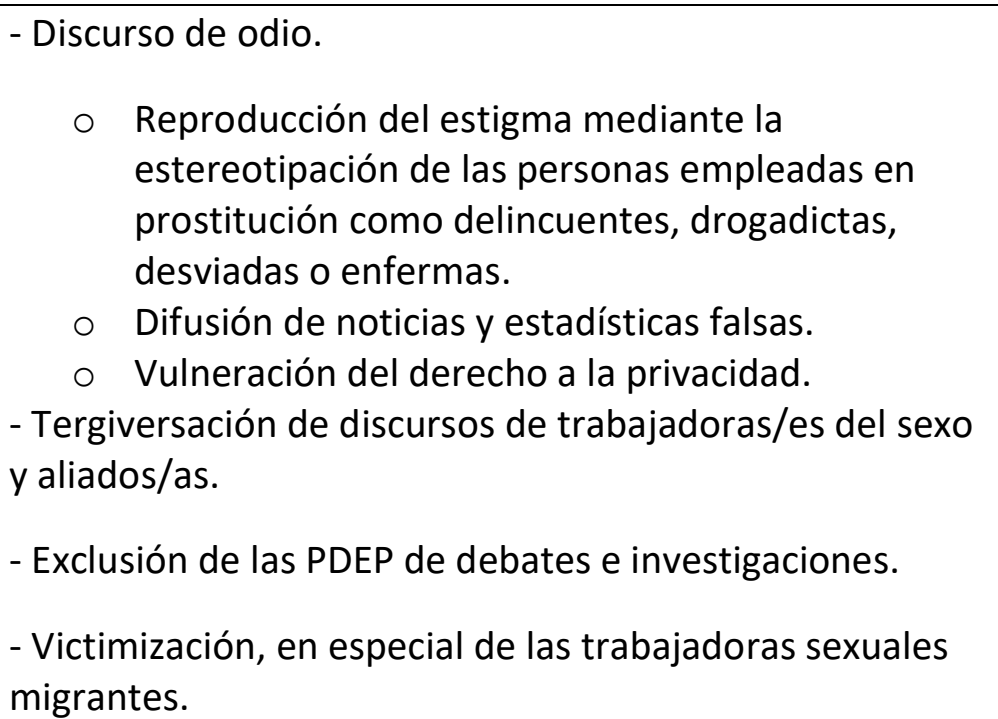 \\
\hline
\end{tabular}

Fuente: Elaboración propia a partir de los resultados del trabajo de campo 


\section{Bibliografía}

Acién, E. (2014). Accesibilidad al Sistema Sanitario Público andaluz de las trabajadoras del sexo nigerianas en el Poniente almeriense. Notas etnográficas. Gazeta de Antropología, 30 (2).

Acién, E. (2015). Trabajadoras sexuales en el Poniente Almeriense. Tesis doctoral. Departamento de Geografía, historia y humanidades de la Universidad de Almería.

Agustín, L.M. (2009). Sexo y marginalidad. Emigración, mercado de trabajo e industria del rescate. Popular: Madrid.

Amaya, A., Canaval, G. E. y Viáfara, E. (2005). Estigmatización de las trabajadoras sexuales: influencias en la salud. Colombia Médica, 36 (2), 65-74.

Amnistía Internacional. (2016a). Política de Amnistía Internacional sobre la obligación del Estado de respetar, proteger y realizar los derechos humanos de las trabajadoras y los trabajadores sexuales. En https://www.amnesty.org/download/Documents/POL3040622016SPANISH.pdf. Accedido el 25 de junio de 2020.

Amnistía Internacional. (2016b). Los trabajadores y trabajadoras sexuales en peligro. Resumen de la investigación sobre los abusos contra los Derechos Humanos de las trabajadoras y los trabajadores sexuales. https://www.amnesty.org/download/Documents/POL4040612016SPANISH.pdf. Accedido el 25 de junio de 2020.

Amnistía Internacional. (2019). "Si ellos pueden tenerla, ¿por qué uno no?". Tortura y otros malos tratos por razón de género contra trabajadoras sexuales en República Dominicana. En https://www.amnesty.org/download/Documents/AMR2700302019SPANISH.PDF. Accedido el 25 de junio de 2020.

Arce, P. (2018). El modelo español de abordaje de la prostitución. Papeles el tiempo de los derechos, (13), 1-29.

Arella, C., Fernández, C., Nicolás, G. y Vartabedian, J. (2007). Los pasos (in)visibles de la prostitución. Estigma, persecución y vulneración de derechos de las trabajadoras sexuales en Barcelona. Virus: Barcelona.

Briz, M. y Garaizabal, C. (Coords.). (2007). La prostitución a debate. Por los derechos de las prostitutas. Talasa: Madrid.

Colectivo Hetaira. (2011). Las putas celebran su día. En https://colectivohetaira.org/2-de-junio-diainternacional-de-las-putas/. Accedido el 25 de junio de 2020.

Colectivo Hetaira. (2016). AFEMTRAS y Hetaira denuncian abusos policiales en el Polígono de Villaverde contra las prostitutas. En https://colectivohetaira.org/afemtras-y-hetaira-denuncianabusos-policiales-en-el-poligono-de-villaverde-contra-las-prostitutas/. Accedido el 25 de junio de 2020.

Comité de Apoyo a las Trabajadoras del Sexo. (2014). Informe septiembre 2015. Evaluación de la 'Ordenanza para luchar contra la prostitución del municipio de Murcia'. Manuscrito inédito.

Comité de Apoyo a las Trabajadoras del Sexo. (2017). Memoria 2017a. Manuscrito inédito.

Comité de Apoyo a las Trabajadoras del Sexo. (2017b). Educación para salud en clientes de prostitución en la Región de Murcia: Estudio de situación y propuesta de actuación. Manuscrito inédito.

Comité de Apoyo a las Trabajadoras del Sexo. (2018). II Informe mayo 2018. Evaluación de la 'Ordenanza para luchar contra la prostitución del municipio de Murcia'. Manuscrito inédito. 
Comité de Apoyo a las Trabajadoras del Sexo. (2020). Discriminación, estigma y discurso de odio en Prostitución. Manuscrito inédito.

Doezema, J. (2004). ¡A crecer! La infantilización de las mujeres en los debates sobre "tráfico de mujeres», en Osborne, R. (Ed.), Trabajador@s del sexo. Derechos, migraciones y tráfico en el siglo XXI. Bellatera: Barcelona: 151-163.

Freixas, A. y Juliano, D. (2008). Un sector susceptible de doble marginación: mujeres mayores que ejercen o han ejercido la prostitución. Anuario de Psicología, 39(1), 93-100.

Garaizabal, C. (2007). El estigma de la prostitución, en Briz, M. y Garaizabal, C. (Coords.), La prostitución a debate. Por los derechos de las prostitutas. Talasa: Madrid: 43-55.

Garaizabal, C. (2008). Las prostitutas toman la palabra: Las vicisitudes de su construcción como sujetos sociales, en Holgado, I (Ed.), Prostituciones. Diálogos sobre el sexo de pago. Icaria: Barcelona: 95-110.

Global Network of Sex Work Projects (NSWP). (2017). El involucramiento significativo de las personas que ejercen el trabajo sexual en el desarrollo de los servicios de salud diseñados para ellas. En https://www.nswp.org/es/resource/el-involucramiento-significativo-de-las-personas-queejercen-el-trabajo-sexual-en-el. Accedido el 25 de junio de 2020.

Goffman, E. (1970). Estigma: la identidad deteriorada. Amorrortu: Buenos Aires.

Holgado, I. (2008). Todas las voces para un mismo concierto feminista, en Holgado, I (Ed.), Prostituciones. Diálogos sobre el sexo de pago. Icaria: Barcelona: 7-40.

Juliano, D. (2002). La prostitución: el espejo oscuro. Icaria: Barcelona.

Juliano, D. (2005). El trabajo sexual en la mira. Polémicas y estereotipos. Cadernos Pagu, (25), 79 106.

Lakuló, N. (2007). En busca de un sueño, en Briz, M. y Garaizabal, C. (Coords.) La prostitución a debate. Por los derechos de las prostitutas. Talasa: Madrid: 93-96.

Ley Orgánica 4/2015, de 30 de marzo, de protección de la seguridad ciudadana. «BOE» núm. 77, de 31 de marzo de 2015. Referencia: BOE-A-2015-3442

López-Riopedre, J. (2011). La criminalización de la industria del sexo, una apuesta políticamente correcta. Gazeta de Antropología, 27(2), 1-18.

López-Riopedre, J. (2012). Una aproximación etnográfica a la prostitución: cuando las trabajadoras sexuales hablan de los clientes. RES: Revista Española de Sociología, (18), 31-62.

Médicos del Mundo Aragón. (2018). Campaña "yo no soy putero". En http://mdmaragon.blogspot.com/2018/09/campanayo-no-soy-putero-yonosoyputero.html.

Accedido el 25 de junio de 2020.

Oñate, S. (2009). Ciudad Nocturna. CAM: Murcia

Ordenanza para luchar contra la prostitución en el Municipio de Murcia. Boletín Oficial de la Región de Murcia. Murcia. 19 de octubre de 2013, núm. 243.

Organización Mundial de la Salud. (2002). Informe mundial sobre la violencia y la salud. Sinopsis. En https://apps.who.int/iris/bitstream/handle/10665/67411/a77102_spa.pdf;jsessionid=38EF67783C EA010D39D7B4D4B7E069E2? sequence=1. Accedido el 25 de junio de 2020.

Osborne, R. (2004). Introducción, en Osborne, R. (Ed.), Trabajador@s del sexo. Derechos, migraciones y tráfico en el siglo XXI. Bellatera: Barcelona: 11-40. 
Osborne, R. (2007). El sujeto indeseado: las prostitutas como traidoras de género, en Briz, M. y Garaizabal, C. (Coords.) La prostitución a debate. Por los derechos de las prostitutas. Talasa: Madrid: 33-42.

Oso, L. (2005). Mujeres inmigrantes y prostitución en Galicia, en Solé, C. y Izquierdo, A. (Coords.), Integraciones diferenciadas: migraciones en Cataluña, Galicia y Andalucía. Anthropos: Barcelona: 119-135.

Oso, L. (2008). Mujeres latinoamericanas en España y trabajo sexual: un laberinto circular, en Herrera, G. y Ramírez, J. (Eds.), América Latina migrante: Estado, familias, identidades. FLACSO: Quito: 223-239.

Oso, L. (2016). Transnational Social Mobility Strategies and Quality of Work Among Latin-American Women Sex Workers in Spain. Sociological Research Online, 21(4), 188-200. https://doi.org/10.5153/sro.4129

Oso, L. y Ulloa, M. (2001). Tráfico e inmigración femenina desde la voz de las mujeres inmigrantes, en Bonelli, E. y Ulloa, M. (Coords.) Tráfico e inmigración de mujeres en España. Colombianas y ecuatorianas en los servicios domésticos y sexuales. ACSUR-Las Segovias: Madrid: 65-119.

Pheterson, G. (2000). El prisma de la prostitución. Talasa: Madrid.

Quiles, M.N. (2019). El estigma social. Convivir con la mirada negativa del otro. Alianza Editorial: Madrid.

Sánchez, P. (2016). Combatiendo el estigma: moral sexual y prostitución. TALES, Revista de filosofía, (6), 195-204.

Sánchez, P. (2018). El feminismo regulacionista no existe, pero el pro-derecho sí. Recuperado de https://www.eldiario.es/tribunaabierta/feminismo-regulacionista-existe-pro-

derechos_6_751784836.html. Accedido el 25 de junio de 2020.

Sanchís. E. (2011). Prostitución voluntaria o forzada. Una contribución al debate. Papers, 96(3), 915936. http://dx.doi.org/10.5565/rev/papers/v96n3.121

Tezanos, J.F. (1999). Tendencias en desigualdad y exclusión social: Tercer foro sobre tendencias sociales. Madrid: Sistema

Valles, M. (2002). Entrevistas cualitativas. Cuadernos metodológicos. Número 32. Centro de Investigaciones Sociológicas: Madrid. 